\title{
Criação e destruição de empregos na indústria metropolitana do nordeste
}

Luís Abel da Silva Filho ${ }^{1}$

Silvana Nunes de Queiroz ${ }^{2}$

Juliana Bacelar de Araújo ${ }^{3}$

Fábio José Ferreira da Silva ${ }^{*}$

Resumo: O mercado de trabalho metropolitano do Nordeste brasileiro é diferenciado de suas áreas de menor projeção econômica. As metrópoles de Fortaleza, Recife e Salvador são detentoras de elevadas quantidades de unidades produtivas de todos os setores de atividade econômica, distinguindo-se das demais áreas da região. O presente estudo analisa o mercado de trabalho e a criação e destruição de postos de trabalho na atividade industrial nas áreas geográficas especificadas - antes e pós-crise econômica de 2008. Para tanto, foram utilizados os dados da Relação Anual de Informações Sociais - RAIS e do Cadastro Geral de Empregados e Desempregados - CAGED, do Ministério do Trabalho e do Emprego - MTE. Metodologicamente, recorre-se a uma revisão de literatura e, em seguida, à construção de indicadores de criação e destruição de vagas no emprego formal metropolitano nordestino. Os resultados mostram relativo destaque da construção civil em relação às demais atividades, e seletividade por idade, escolaridade e faixa de remuneração As metrópoles apresentaram piora nos indicadores do emprego industrial da região e mantiveram as diferenças entre si.

Palavras-chave: Emprego formal; Indústria, Criação e destruição, Regiões Metropolitanas do Nordeste.

JEL: Joo, J6

1 Professor do Departamento de Economia da Universidade Regional do Cariri - URCA. E-mail: abeleconomia@hotmail.com

2 Professora do Departamento de Economia da Universidade Regional do Cariri - URCA. E-mail: silvanaqueirozce@yahoo.com.br

3 Graduada em Ciências Econômicas pela Universidade Federal de Pernambuco (UFPE); Mestrado em Desenvolvimento Econômico pela Universidade Estadual de Campinas (UNICAMP). Doutoranda em Desenvolvimento Econômico na Universidade Estadual de Campinas. E-mail: julianabacelararaujo@gmail.com 4 Graduado em Economia pela Universidade de São Paulo (USP) e Mestrado em Economia de Empresas pela Fundação Getúlio Vargas - SP; Analista do Banco Central do Brasil. E-mail: Silva.fabio11@hotmail.com * As opiniões expressas neste artigo são de inteira responsabilidade do autor e não refletem, necessariamente, a opinião do Banco Central do Brasil. 


\title{
Job creation and destruction in the metropolitan Northeast industrial
}

\begin{abstract}
The metropolitan labor market in Northeast Brazil is distinguished from their areas of lower economic projection. The cities of Fortaleza, Recife and Salvador are holding large amounts of production units from all sectors of economic activity, distinguished from other areas of the region. This study analyzes the labor market and the creation and destruction of jobs in manufacturing activity in specified geographic areas - before and after economic crisis of 2008. Therefore, the data from the Annual Social Information have been used-and RAIS the General Register of Employment and Unemployment - CAGED, the Ministry of Labor and Employment - MTE. Methodologically, it resorts to a literature review and then to the construction of indicators of creation and destruction of jobs in the metropolitan Northeast formal employment. The results show featured on the building in relation to other activities, and selectivity by age, education and range of remuneration. The cities showed worsening in industrial employment indicators in the region and kept the differences.
\end{abstract}

Key-Words: Formal employment, Industry, Creation and destruction, The metropolitan areas of the Northeast.

JEL Classification: Joo, J6

\section{Introdução}

Com base no estudo realizado pelo relatório do Grupo de Trabalho para o Desenvolvimento do Nordeste - GTDN, que constatou aumento da disparidade no nível de desenvolvimento entre o Nordeste e o Sudeste do país, com o crescimento nesta da concentração industrial, o Nordeste tem sido alvo de estudos relacionados ao desenvolvimento econômico regional e objeto de promoção de políticas nacionais de desenvolvimento regional (Pacheco, 1999; Araújo, 2000; Furtado, 2007; Cano, 2008). Nesse contexto, as políticas de incentivos coordenadas pela Superintendência de Desenvolvimento do Nordeste - SUDENE, além dos investimentos federais em infraestrutura, e, mais adiante, o papel do bloco de investimentos do II Plano Nacional de Desenvolvimento - PND foram fundamentais para a desconcentração produtiva e a distribuição espacial dos investimentos para a região (Guimarães Neto, 1997; Pacheco, 1998). 
A ausência de uma política nacional de desenvolvimento regional tem fortalecido a guerra fiscal entre os Estados da região e mostra o viés de seleção de atividades produtivas ${ }^{1}$. Nos anos 1990, coube aos estados do Nordeste a captação de indústrias trabalho/intensivas, a exemplo da têxtil, de confecções e calçadista. Todavia, nos anos 2000 , verifica-se a atração para a região de indústrias mais intensivas em capital, como a indústria automotiva, na Bahia, e a indústria química e de alimentos e bebida, em Pernambuco, mas todas com aportes de incentivos fiscais.

Nesse cenário, a dinâmica do mercado de trabalho mostra-se relativamente vinculada às atividades econômicas industriais acima referidas, o que permite contratação da força de trabalho em condições salariais e de trabalho relativamente díspares em relação às outras regiões brasileiras (Arraes et al., 2008). Além disso, as novas formas de contratos de trabalho instituídas nos anos de 1990 afetaram sobremaneira o emprego nacional (Pochmann, 1998; 1999; 2001; Baltar \& Proni, 1995; Baltar et al., 1996; Dedecca, 1998; 2005) e regional com intensidade considerável (Silva Filho \& Clementino, 2011). Todavia, a partir de meados dos anos 2000, registrou-se a retomada da geração de emprego, puxada especialmente pelos postos de trabalho com proteção social (Dedecca \& Rosandiski, 2006; Araujo, 2013).

As taxas médias de crescimento do emprego industrial metropolitano têm-se mostrado satisfatórias nos anos iniciais do século XXI, mas com especificidades significativas no contexto do mercado de trabalho industrial. No que se refere à criação e destruição de postos de trabalho, tem-se observado pouca representatividade do setor supracitado no saldo de vagas do mercado formal de trabalho metropolitano, sendo elencada a criação de postos de trabalho nos serviços e comércio, destacando-se a construção civil (Silva, 2012).

Diante disso, este artigo tem como cerne central de investigação a análise do dinamismo do emprego industrial nas regiões metropolitanas (Fortaleza, Recife e Salvador) do Nordeste brasileiro, antes e pós-crise econômica de 2008. As áreas metropolitanas são selecionadas pelo fato de concentrarem sobremaneira as atividades produtivas industriais, além de parte significativa da PEA - cerca de 50,0\% da metropolitana do Recife, conforme atesta Silva (2012), e de apresentarem com maior nível de consistência a dinâmica da criação e destruição de postos de trabalho no setor em questão.

Para atingir os objetivos propostos pelo estudo, o artigo encontra-se assim estruturado: além das considerações iniciais, a segunda seção aborda os procedimentos metodológicos, com o fito de esclarecer informações acerca da base de dados e do método proposto; na terceira seção, apresenta-se a dinâmica do emprego industrial no Nordeste metropolitano, à luz da conjuntura setorial 
e das formas de contratos de trabalho no setor industrial; na quarta seção, a criação e a destruição de postos de trabalhos são tratadas empiricamente; e, por último, na quinta seção, tecem-se as considerações finais.

\section{Procedimentos metodológicos}

Para o desenvolvimento da pesquisa, tornam-se oportunos alguns detalhamentos acerca da área investigada e da base de dados e método utilizado no estudo. Utilizaram-se como recorte geográfico as três regiões metropolitanas do Nordeste: Fortaleza, Recife e Salvador, no período que compreende os anos de 2005-2006 e 2011-2012, ou seja, um momento antes e outro pós-crise econômica de 2008. Esses anos foram selecionados com o intuito de não viesar a dinâmica do emprego industrial pelo choque da crise. Conforme Corseuil et al. (2002b), a série em curto espaço de tempo propõe o não viesamento do indicador de criação e destruição de postos de trabalho com os choques macroeconômicos.

Nesse caso, tem-se, por definição, o período inicial $t_{0}(2005 ; 2011)$ e o período final $t_{1}(2006 ; 2012)$, na constituição do primeiro e do segundo biênios, respectivamente. Trata-se da média do estoque de ocupados em cada ano no dia 31/12 (RAIS-MTE) ${ }^{2}$, para constituir o primeiro biênio (2005-2006) e, da mesma forma, o segundo (2011-2012). Adicionalmente, recorre-se ao banco de dados do CAGED-MTE ${ }^{3}$ para observar o comportamento da admissão e da demissão de mão de obra nos setores especificados.

Os dados presentes nesse artigo referem-se ao emprego industrial das regiões metropolitanas em análise, salvo as tabelas que tratam de todos os grandes setores de atividade econômica considerados pelo IBGE (extrativa mineral; indústria de transformação; serviços industriais de utilidade pública; construção civil; comércio; serviços; administração pública; agropecuária, extração vegetal, caça e pesca). Como atividade industrial, para fins deste estudo, considera-se o somatório dos postos de trabalho na indústria extrativa mineral, indústria de transformação e serviços industriais de utilidade pública.

Baseado numa série de investigações acerca da rotatividade no mercado de trabalho brasileiro (Corseuil et al., 2002a; 2002b; Orellano \& Pazello, 2006; Ribeiro, 2001; Cacciamali; 1992), e convergindo com alguns estudos realizados por Silva Filho (2012), Silva Filho \& Silva (2013) dentre outros, este trabalho investiga somente a criação e destruição de postos de trabalho

2 O Banco de dados da RAIS-MTE contém informações acerca do estoque total de ocupados desde a escala municipal até a nacional, em todos os setores de atividades econômicas consideradas pelo IBGE e pela CNAE, conforme base de registros administrativos dos ocupados formalmente no dia 31/12 de cada ano calendário.

3 O CAGED-MTE registra o movimento mensal e anual (fluxo de mão de obra) desde a escala municipal até a nacional, em todos os setores de atividades econômicas consideradas pelo IBGE e pela CNAE. 
industrial metropolitanos do Nordeste, considerando também, as características demográficas e socioeconômicas dos ocupados. Desse modo, atributos como idade, sexo, escolaridade, além da remuneração média dos postos de trabalho no setor $i$ no tempo $t$ influenciam a análise.

Desta forma, e com base nos estudos referenciados acima, a taxa de criação pode ser assim especificada:

$$
J C_{i t}=\sum_{i=1}^{N}\left[\left(\frac{A D_{i t}}{X_{i t 0}+X_{i t 1} / 2}\right) I\left(A D_{i t}>0\right)\right]
$$

Onde, $J C_{i t}=$ taxa de criação de postos de trabalho; $A D_{i t}=$ número de admitidos no setor e no tempo, respectivamente; $X_{i t 0}+X_{i t 1} / 2=$ a média do estoque total de ocupados em $\boldsymbol{t}_{\mathrm{o}}$ e $\boldsymbol{t}_{1}$ no setor e no tempo, respectivamente, considerando-se o fluxo e o estoque anual. Para a criação, tem-se que $A D_{i t}>0$.

A forma simétrica indica que a taxa de destruição de postos de trabalho pode ser especificada da forma que se segue:

$$
J D_{i t}=\sum_{i=1}^{N}\left[\left(\frac{D E_{i t}}{X_{i t 0}+X_{i t 1} / 2}\right) I(D E>0)\right]
$$

Com isso, $J D_{i t}$ representa a destruição de postos de trabalho em que acontece se, e somente se, $D E>0$.

Adicionalmente, haverá criação líquida de vagas se:

$$
N E G_{i t}=\sum_{i=1}^{N}\left[\left(J C_{i t}-J D_{i t}\right) I(N E G>0)\right]
$$

$N E G_{i t}$ aqui é a taxa de criação líquida de postos de trabalho. no caso de $N E G>0$, têm-se criação líquida; caso contrário, destruição líquida.

A partir daí, é possível observar o comportamento do setor industrial nas metrópoles nordestinas mediante observação de sua performance em relação ao tempo. Resultados positivos do indicador NEG apontam bom desempenho da atividade industrial, de acordo com a sua magnitude, que pode ser quantificada a partir dos indicadores acima discriminados; os resultados negativos denunciam os efeitos macroeconômicos sobre a queima de postos de trabalho no setor. 


\section{Dinâmica do Emprego Industrial no Nordeste}

A dinâmica econômica regional brasileira tem-se mostrado díspar entre as macrorregiões (Araújo, 2000; Cano, 2002). Dentro do contexto regional, o mercado de trabalho sempre revelou resquícios de forte segmentação setorial e, ainda, forte concentração em áreas mais prósperas do ponto de vista econômico. Com efeito, as áreas metropolitanas nordestinas foram sobremaneira beneficiadas com a concentração de atividades produtivas em todo o seu contexto histórico em relação ao interior da região (Menezes e Carvalho, 1999).

Porém, divergências entre essas áreas são constatadas em estudos que têm em mira abordar as disparidades dentro do contexto regional (Galeano et al., 2011; Silva Filho et al., 2012). Fatores como incentivos à criação de unidades produtivas de reflexos mais amplos na formação de aglomerados condicionam a concentração industrial em cadeias produtivas inter-relacionadas em algumas áreas do Nordeste brasileiro. Como exemplo, destacam-se o polo petroquímico e a Ford do Brasil no estado da Bahia (Galeano et al., 2011).

Nessa conjuntura, a geração de postos de trabalho revela-se concentrada nas áreas eleitas pelo capital produtivo, deixando as demais na perspectiva incansável de que haja uma política de desconcentração produtiva pautada nos incentivos fiscais. Esse método, utilizado na região, sobretudo a partir dos anos 1990, é de relevância no contexto das políticas de interiorização industrial no Nordeste brasileiro. Todavia, alguns estudos têm elucidado a pouca eficiência da desconcentração pautada somente em incentivos fiscais ${ }^{4}$.

\subsection{Caracterização setorial do mercado de traba- lho formal nas regiões metropolitanas do Nordeste brasileiro}

No que se refere ao número de postos formais de trabalho, considerando-se os setores do IBGE, os dados da tabela 01 mostram que a região metropolitana de Salvador sobressai em relação às demais, em virtude de sua maior capacidade empregatícia. A região metropolitana de Recife, por sua vez, ocupa a segunda posição no ranking, deixando a grande Fortaleza com a menor quantidade (2005-2006).

Em todas as regiões metropolitanas, há predominância do setor de serviços, seguido pela administração pública. Em ambos os setores, a grande Salvador supera as demais RM analisadas. Por sua vez, a indústria extrativa mineral e a agropecuária, silvicultura, caça e pesca, são, respectivamente, os setores com menores incidências de vínculos nos estoques de empregos formais no biênio 2005-2006. Isso se dá pelo fato de serem atividades desenvolvidas em

No Ceará, ver, por exemplo, Pontes et al. (2006); Silva Filho \& Queiroz (2009). 
áreas rurais e/ou distantes de aglomerados urbanos.

TABELA 1: NÚMEROS DE OCUPADOS FORMAIS POR SETOR DE ATIVIDADE ECONÔMICA NAS REGIÕES METROPOLITANAS DE FORTALEZA, RECIFE E SALVADOR 2005-2006/2011-2012

\begin{tabular}{|c|c|c|c|c|c|c|c|c|}
\hline \multirow{2}{*}{ IBGE Setor } & \multicolumn{3}{|c|}{$2005 / 2006$} & \multicolumn{3}{|c|}{$2011 / 2012$} & \multicolumn{2}{|r|}{$\Delta \%$} \\
\hline & FOR & REC & SAL & FOR & REC & SAL & FOR & REC SAL \\
\hline $\begin{array}{l}\text { Extrativa } \\
\text { mineral }\end{array}$ & 1.082 & 846 & 2.426 & 1.547 & 1.043 & 2.867 & 43,0 & $23,4 \quad 18,2$ \\
\hline $\begin{array}{l}\text { Indústria de } \\
\text { transformação }\end{array}$ & 127.800 & 85.412 & 66.731 & 172.347 & 117.240 & 92.716 & 34,9 & $37,3 \quad 38,9$ \\
\hline $\begin{array}{l}\text { Serviços Ind. } \\
\text { de Uti. Púb. }\end{array}$ & 5.818 & 11.996 & 10.023 & 5.084 & 11.205 & 14.364 & $-12,6$ & $-6,643,3$ \\
\hline $\begin{array}{l}\text { Construção } \\
\text { Civil }\end{array}$ & 26.537 & 36.024 & 52.864 & 74.079 & 118.919 & 109.641 & 179,2 & $230,1107,4$ \\
\hline Comércio & 101.050 & 120.400 & 126.490 & 169.538 & 187.507 & 174.609 & 67,8 & $55,738,0$ \\
\hline Serviços & 226.999 & 276.269 & $345 \cdot 741$ & 358.135 & 444.876 & 486.154 & 57,8 & $61,040,6$ \\
\hline $\begin{array}{l}\text { Administração } \\
\text { Pública }\end{array}$ & $145 \cdot 321$ & 195.632 & 236.987 & 192.333 & 228.347 & 234.901 & 32,4 & $16,7-0,9$ \\
\hline $\begin{array}{l}\text { Agrop., ext. } \\
\text { veg., caça e } \\
\text { pesca }\end{array}$ & 5.773 & 8.708 & 3.576 & 7.125 & 8.009 & 2.005 & 23,4 & $-8,0-43,9$ \\
\hline Total & 640.379 & 735.285 & 844.836 & 980.188 & 1.117.144 & .117 .254 & 53,1 & $51,932,2$ \\
\hline
\end{tabular}

Fonte: elaborado pelos autores a partir de dados da RAIS/MTE, 2014.

No segundo biênio analisado (2011-2012), os dados ratificam as posições mencionadas no que se refere ao ranking de capacidade empregatícia formal. No entanto, cabe destacar que as regiões metropolitanas de Recife (1.117.144) e Salvador (1.117.254) ultrapassaram um milhão de postos formais de trabalho, e a grande Fortaleza (980.188) ficou próxima dessa estatística. Além do mais, é pertinente frisar que se reduziu a distância entre a grande Recife e a grande Salvador, no tocante à capacidade de geração de postos formais de trabalho. No caso da Região Metropolitana do Recife, conforme atesta Silva (2012), constata-se um importante volume de obras de infraestrutura e a formação de um novo aglomerado industrial, a partir da consolidação do complexo indústria e portuário de Suape, incrementando, assim, a dinâmica e a formalidade no mercado de trabalho.

Todavia, parte importante dos grandes investimentos industriais na região ainda se acha em fase de construção. As grandes obras de Suape e seu efeito 
satélite na RM do Recife têm elevado sobremaneira o número de postos formais de trabalho. Isso fica claro quando se observa o crescimento da construção civil na geração de empregos com registro em carteira. A grande Recife apresenta a maior taxa de crescimento em relação às demais $(230,1 \%)$, mesmo que esse setor tenha apresentado bom desempenho nas três metrópoles em tela. Em linhas gerais, cabe destacar que a grande Fortaleza apresentou a maior taxa de crescimento do estoque de postos formais de trabalho $(53,1 \%$ no período), mas ainda detém um estoque inferior ao das demais. Além disso, considerando-se um período relativamente curto, todas elas apresentaram bom desempenho, mesmo que a grande Salvador $(32,2 \%)$ tenha experimentado a menor taxa de crescimento.

Em relação ao incremento no total de ocupados formais, a indústria de transformação, a extrativa mineral, o comércio e os serviços tiveram desempenho considerável em todas as regiões metropolitanas ${ }^{5}$. Todavia, alguns dos setores em observação apresentaram divergência em relação ao crescimento entre as metrópoles, tais como: serviços industriais de utilidade pública (variação negativa na grande Fortaleza e grande Recife), administração pública (variação negativa na grande Salvador), agropecuária, extração vegetal, caça e pesca (variação negativa na metropolitana de Recife e de Salvador).

O desempenho da geração de postos formais de trabalho nessas regiões é resultado de um conjunto de fatores, com destaque para a retomada do crescimento econômico, expansão do consumo, crédito e melhoria da renda, políticas de ampliação da base produtiva e infraestrutura regional, especialmente através do Programa de Aceleração do Crescimento (PAC), que trouxe importantes investimentos produtivos, além de obras que têm contribuído sobremaneira para a infraestrutura regional, tais como a melhoria de estradas e a ampliação de obras de portos e aeroportos, com o fito de proporcionar maior integração com os demais continentes (Araújo, 2013).

\subsection{Formas de inserção da mão de obra no mercado for- mal de trabalho nas regiões metropolitanas do Nordeste brasileiro}

Do ponto de vista do tipo de admissão da força de trabalho nas regiões metropolitanas estudadas e nas atividades industriais aqui estabelecidas, podem-se observar diferenças significativas entre elas. No primeiro biênio, a grande Fortaleza apresentou a maioria absoluta, quando comparada às demais, na contratação por primeiro emprego (10.279). Além disso, a metropolitana de Salvador se destacou pela menor quantidade de admissão nesse aspecto (4.654). 
Oportunamente, destaque-se que a metrópole de Fortaleza tem maior número de ocupados formais nas atividades produtivas industriais (134.700). Isso se dá, possivelmente, pelo fato de as atividades da indústria têxtil e calçadista (setores da indústria de transformação) terem grande representatividade nessa região (Silva Filho \& Queiroz, 2012), nas atividades trabalho/intensivo, que divergem de unidades produtivas capital/intensivo, a exemplo de algumas importantes que operam na metropolitana de Salvador (Galeano et al., 2011). Nesse caso, há maior capacidade de geração de postos de trabalho na primeira ${ }^{6}$.

No segundo biênio, mantém-se a grande Fortaleza como o maior estoque de ocupados nas atividades industriais (178.978), seguida de Recife (129.488) e de Salvador (109.946). A maior variação percentual, porém, aconteceu com a última (38,9\% no período). Outrossim, a admissão em primeiro emprego, entre 2011 e 2012, também foi mais acentuada na metropolitana de Fortaleza (13.225), bem como aquela em reemprego (24.163). Ressalte-se que a distribuição dos ocupados por tipo de admissão da força de trabalho industrial mostrou-se relativamente semelhante ao observado no primeiro biênio, sem nenhuma mudança significativa nas formas de contratação já observadas.

TABELA 02: NÚMERO DE OCUPADOS FORMAIS NA INDÚSTRIA7 NAS REGIÕES METROPOLITANAS DE FORTALEZA, RECIFE E SALVADOR, SEGUNDO O TIPO DE ADMISSÃO - 2005-2006/2011-2012

\begin{tabular}{l|ccc|ccc|ccc}
\hline \multirow{2}{*}{ Tipo Admissão } & \multicolumn{3}{|c|}{$2005 / 2006$} & \multicolumn{3}{c|}{$2011 / 2012$} & \multicolumn{3}{c}{$\triangle \%$} \\
\cline { 2 - 9 } & FOR & REC & SAL & FOR & REC & SAL & FOR & REC & SAL \\
\hline $\begin{array}{l}\text { Não Admitido } \\
\text { Ano }\end{array}$ & 93.899 & 67.581 & 55.546 & 119.439 & 83.321 & 76.105 & 27,2 & 23,3 & 37,0 \\
$\begin{array}{l}\text { Primeiro } \\
\text { Emprego }\end{array}$ & 10.279 & 5.138 & 4.654 & 13.225 & 7.022 & 4.549 & 28,7 & 36,7 & $-2,3$ \\
Reemprego & 28.394 & 23.881 & 16.655 & 42.163 & 36.336 & 26.230 & 48,5 & 52,2 & 57,5 \\
$\begin{array}{l}\text { Transferência } \\
\text { com Ônus }\end{array}$ & 267 & 520 & 566 & 151 & 196 & 233 & $-43,3$ & $-62,3$ & $-58,8$ \\
$\begin{array}{l}\text { Transferência } \\
\text { sem Ônus }\end{array}$ & 1.824 & 1.106 & 1.752 & 3.904 & 2.540 & 2.817 & 114,1 & 129,8 & 60,8 \\
Reintegração & 28 & 18 & 5 & 96 & 74 & 14 & 249,1 & 308,3 & 170,0 \\
Reversão & 1 & 1 & 0 & 0 & 0 & 0 & $-100,0$ & $-100,0$ & $-100,0$ \\
Outros & 11 & 9 & 3 & 0 & 0 & 0 & $-100,0$ & $-100,0$ & $-100,0$ \\
Total & $\mathbf{1 3 4 . 7 0 0}$ & $\mathbf{9 8 . 2 5 3}$ & $\mathbf{7 9 . 1 7 9}$ & $\mathbf{1 7 8 . 9 7 8}$ & $\mathbf{1 2 9 . 4 8 8}$ & $\mathbf{1 0 9 . 9 4 6}$ & $\mathbf{3 2 , 9}$ & $\mathbf{3 1 , 8}$ & $\mathbf{3 8 , 9}$ \\
\hline
\end{tabular}

Fonte: elaborado pelos autores a partir de dados da RAIS/MTE, 2014.

6 Não faz parte da proposta deste estudo discutir a qualidade dos postos de trabalhos em atividades trabalho/intensivo e/ou capital/intensivo.

7 Consideram-se os ocupados na indústria extrativa mineral, indústria de transformação e serviços industriais de utilidade pública. 


\section{Criação e destruição de postos de trabalho na indústria das regioes metropolitanas do Nordeste}

A dinâmica recente do mercado de trabalho, sobretudo no pertinente ao desempenho das atividades econômicas no seu processo de expansão e criação de novas vagas, é resultado da favorável conjuntura macroeconômica brasileira, que se registra desde o final de 2003 (Dedecca \& Rosandiski, 2006) e com mais intensidade, a partir de 2005 (Cintra, 2005). Assim é que, o desempenho dos setores de atividade econômica reflete os avanços e/ou retrocessos da economia no período em análise.

Destarte, pode-se observar no primeiro biênio que há divergência na dinâmica do emprego nas regiões metropolitanas consideradas. Enquanto a construção civil foi destaque na grande Fortaleza, com criação líquida de 0,15 , assim como o comércio $(0,06)$, na metropolitana de Recife o setor de extração mineral deu o maior impulso na criação de novas vagas $(0,19)$, seguido do comércio (0,06). Já em Salvador, destacaram-se, mesmo que modestamente, a extrativa mineral $(0,05)$, a indústria de transformação $(0,05)$ e o comércio $(0,05)$. Destaque-se também que o setor de serviços industriais de utilidade pública apresentou queima de postos de trabalho $(-0,01)$, no primeiro biênio em observação, na RMS.

No segundo biênio, opera-se relativa mudança no comportamento do mercado de trabalho, segundo o setor de atividade econômica. As três regiões metropolitanas em análise modificaram acentuadamente a dinâmica do emprego formal. Na grande Fortaleza, registrou-se queima de postos de trabalho nos serviços industriais de utilidade pública $(-0,01)$ e na construção civil $(-0,03)$. $\mathrm{O}$ que pode ser justificado pelo fato de se haver concluído grandes empreendimentos realizados em anos pretéritos, a exemplo das obras da copa do mundo de 2014, bem como parte das obras de ampliação de infraestrutura nos portos nessa área. Nessa RM a taxa de criação líquida recuou levemente: baixou de 0,03 no primeiro para 0,02 no último biênio.

Já na grande Recife, o que realça é a redução da taxa de criação líquida da indústria extrativa mineral para 0,05, além da elevação acentuada do setor de construção civil para 0,09. Ainda se faz oportuno frisar a queima de postos de trabalho no setor de serviços industriais de utilidade pública $(-0,01)$ e o modesto desempenho dos demais setores (ver tabela 03). Tais fatos ensejaram apenas taxa de 0,03 na criação líquida de postos formais de trabalho no último biênio, repetindo-se, assim, o resultado observado no primeiro. 
TABELA O3: CRIAÇÃO, DESTRUIÇÃO E SALDO DE VAGAS NOS MERCADO DE TRABALHO FORMAL METROPOLITANO SEGUNDO OS SETORES DO IBGE 2005-2006/2011-2012.

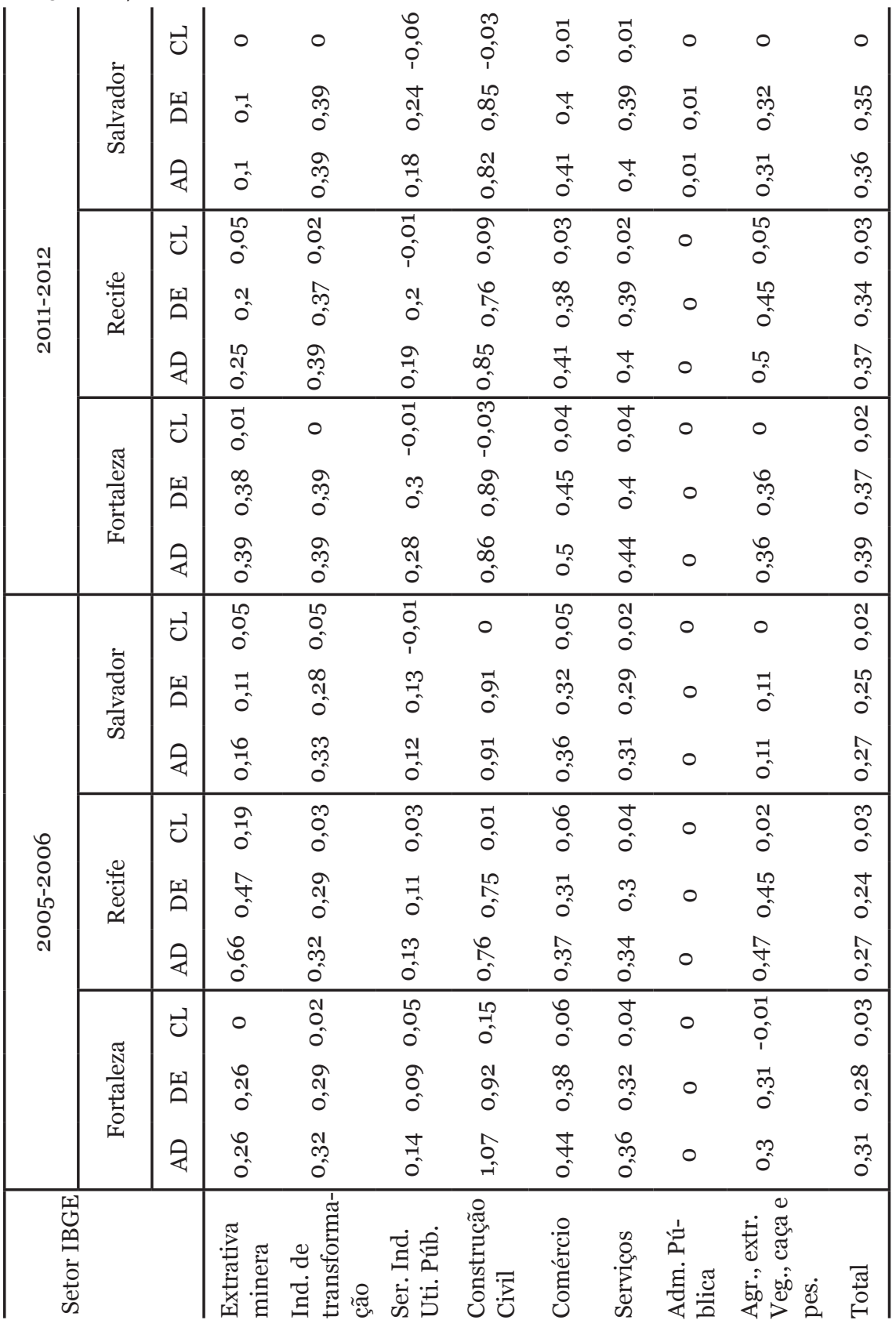

Fonte: elaborado pelos autores a partir de dados da RAIS-CAGED/MTE, 2014. 
Já na região metropolitana de Salvador, registraram-se importantes taxas de destruição de postos de trabalho no setor de serviços industriais de utilidade pública $(-0,06)$ e na construção civil $(-0,03)$. Além disso, o desempenho do mercado formal de trabalho foi pouco expressivo no contexto da geração de novas vagas. $\mathrm{O}$ que se teve, de fato, foi uma taxa de criação líquida estatisticamente próxima de zero no segundo biênio analisado. A retração dos setores que queimaram vagas, acoplada ao baixo desempenho dos demais, contribuiu para os resultados encontrados na grande Salvador.

Na tabela 04, vê-se o desempenho do emprego industrial nas três regiões metropolitanas, a partir do tamanho do estabelecimento ${ }^{8}$. Essa metodologia é constatada em Pazzelo et al. (2000) e Corseuil et al. (2002). Para eles, o tamanho do estabelecimento reflete os avanços e retrocessos macroeconômicos, demostrando o comportamento do mercado em relação a esse movimento. Assim, as maiores indústrias refletem o desempenho do mercado na dinâmica da produção atacadista e/ou com o fito de inserção externa. As menores unidades produtivas refletem com mais precisão a dinâmica do mercado varejista interno, diante da performance do mercado.

O que se há, de fato, é o desempenho elevado do microestabelecimento na geração de postos formais de trabalho nas três regiões metropolitanas: no biênio 2005-2006, a grande Fortaleza apresentou saldo de vagas elevado no microestabelecimento $(0,19)$, o maior, entre as três RM comparadas, com queima de postos de trabalho no médio $(-0,04)$ e no grande $(-0,01)$ estabelecimento, além de baixo desempenho no pequeno $(0,01)$.

Já a metrópole recifense teve saldo líquido positivo de vagas em todos os perfis de estabelecimentos industriais. Todavia, é oportuno ressaltar que foi no microestabelecimento que se operou o melhor desempeno $(0,12)$. $O$ pequeno estabelecimento registrou saldo de 0,02, ficando saldo de 0,01 para o médio e o grande estabelecimento industrial. Esse resultado proporcionou saldo líquido de 0,03 no setor industrial dessa área metropolitana.

Já na grande Salvador, o pequeno e o médio estabelecimento industrial apresentaram saldo de 0,03, com saldo de 0,02 para o grande estabelecimento. No entanto, foi no microestabelecimento que se observou a melhor performance na geração de postos formais de trabalho, com criação líquida de 0,14 no biênio 2005-2006. Vê-se assim, que o microestabelecimento apresentou a maior capacidade de geração de postos de trabalho nas três regiões metropolitanas em apreço.

No segundo biênio, pode-se perceber que a região metropolitana de Fortaleza apresentou queima de postos de trabalho em todos os tamanhos de estabelecimentos industriais. A exceção ficou por conta do micro com saldo de vagas de 0,15 . Porém, o baixo desempenho dos demais estabelecimentos conferiu saldo estatisticamente próximo de zero. Já a grande Recife teve desempenho 
mais modesto no micro estabelecimento $(0,07)$, mas com saldo de vagas em todos os demais, o que lhe conferiu criação líquida de 0,02.

Na região metropolitana de Salvador, mesmo com saldo de o,12 registrado no microestabelecimento industrial, a performance do mercado de trabalho nas indústria de médio e grande porte não ensejou desempenho satisfatório da atividade industrial na geração de postos formais de trabalho. O que houve, na verdade, foi queima de postos de trabalho na ordem de -0,01 no biênio 2011-2012. As indústrias médias e grandes demitiram a taxas superiores às das admissões, provocando a redução do saldo de vagas gerado pela microindústria, no computo final. 


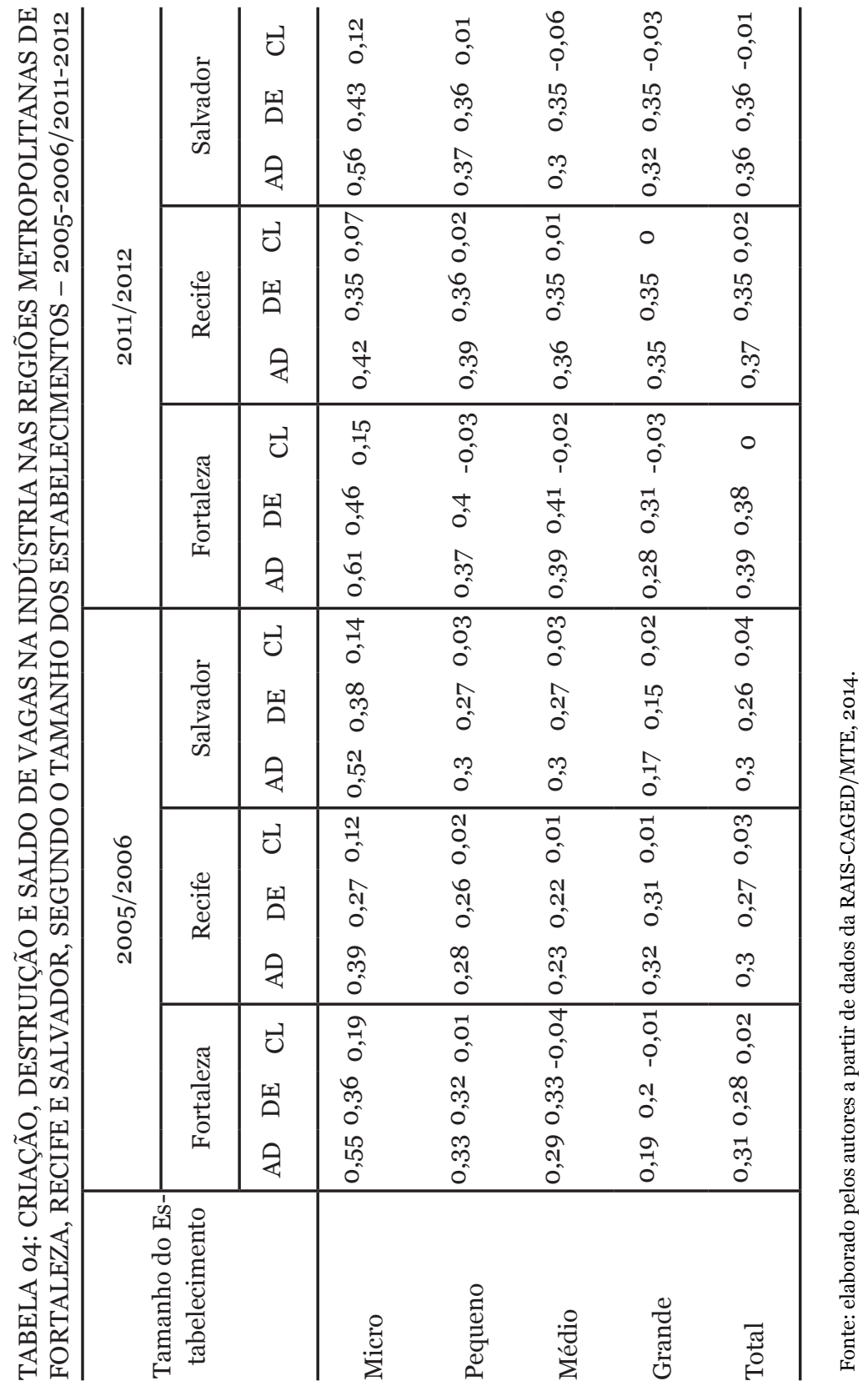




\subsection{Caracterização demográfica}

Alguns trabalhos na literatura internacional (Márquez \& Pages, 1998; Freije, 2001, Corbacho, 2002; Funkhouser, 1996; Marcoullier et al.,1997) e nacional (Bruschini \& Puppin, 2004; Bruschini, 2007; Silva Filho, 2011; Miro e Suliano 2010; Silva Filho \& Amon-Há, 2011; Silva Filho \& Clementino, 2011) mostram que as características demográficas da força de trabalho (idade, raça/cor, sexo) têm forte influência nos padrões de formalidade do mercado de trabalho, bem como na determinação de salários e permanência no desemprego. Nesse caso, observam-se algumas dessas características para se verificar o comportamento do emprego industrial.

Conforme a tabela 05, as mulheres apresentam menor movimento de entrada e de saída na força de trabalho industrial da grande Fortaleza. Consoante os registros, a criação líquida foi superior para os homens, mas com saldo líquido também para as mulheres nessa RM. Na metropolitana do Recife, os registros atestam saldo de vagas estatisticamente igual para homens e mulheres no biênio em discussão (2005-2006). Já na grande Salvador, os homens lograram saldo de vagas levemente superior ao das mulheres. Todavia, foi nessa $\mathrm{RM}$ que as mulheres registraram o maior saldo de vagas, em comparação às demais metrópoles sob análise.

No segundo biênio (2011-2012), os registros contêm resultados estatisticamente próximos de zero na grande Fortaleza, tanto para os homens quanto para as mulheres, sendo que na metropolitana do Recife elas se destacaram sobremaneira com saldo de vagas considerável $(0,04)$ e superior ao observado para a força de trabalho masculina (o,01). Ademais, na metropolitana de Salvador, os dados mostram que a força de trabalho masculina foi responsável pela queima de postos de trabalho, e a feminina apresentou leve criação líquida.

O que se verifica pelas informações plotadas na tabela o5 é que não há divergência acentuada no que se refere ao sexo, para a determinação do movimento de entrada e saída da força de trabalho no setor industrial, no período em análise. Ou seja, ser mulher não implicou ter maiores ou menores taxas de admissão ou demissão no emprego industrial das áreas em estudo. Contudo, elas permanecem sendo minoria absoluta no estoque total de ocupados no mercado de trabalho industrial nordestino e brasileiro (Silva Filho, 2012).

Diferentemente do encontrado com a variável anterior (sexo), a variável idade reforça o observado em outros estudos que tratam da seletividade do mercado de trabalho, considerando características demográficas. Na metrópole de Fortaleza, no biênio 2005-2006, registaram-se taxas de criação líquida negativa para a força de trabalho industrial com idade acima de 30 anos. Nessa RM, observa-se criação líquida positiva apenas nas primeiras faixas etárias. 


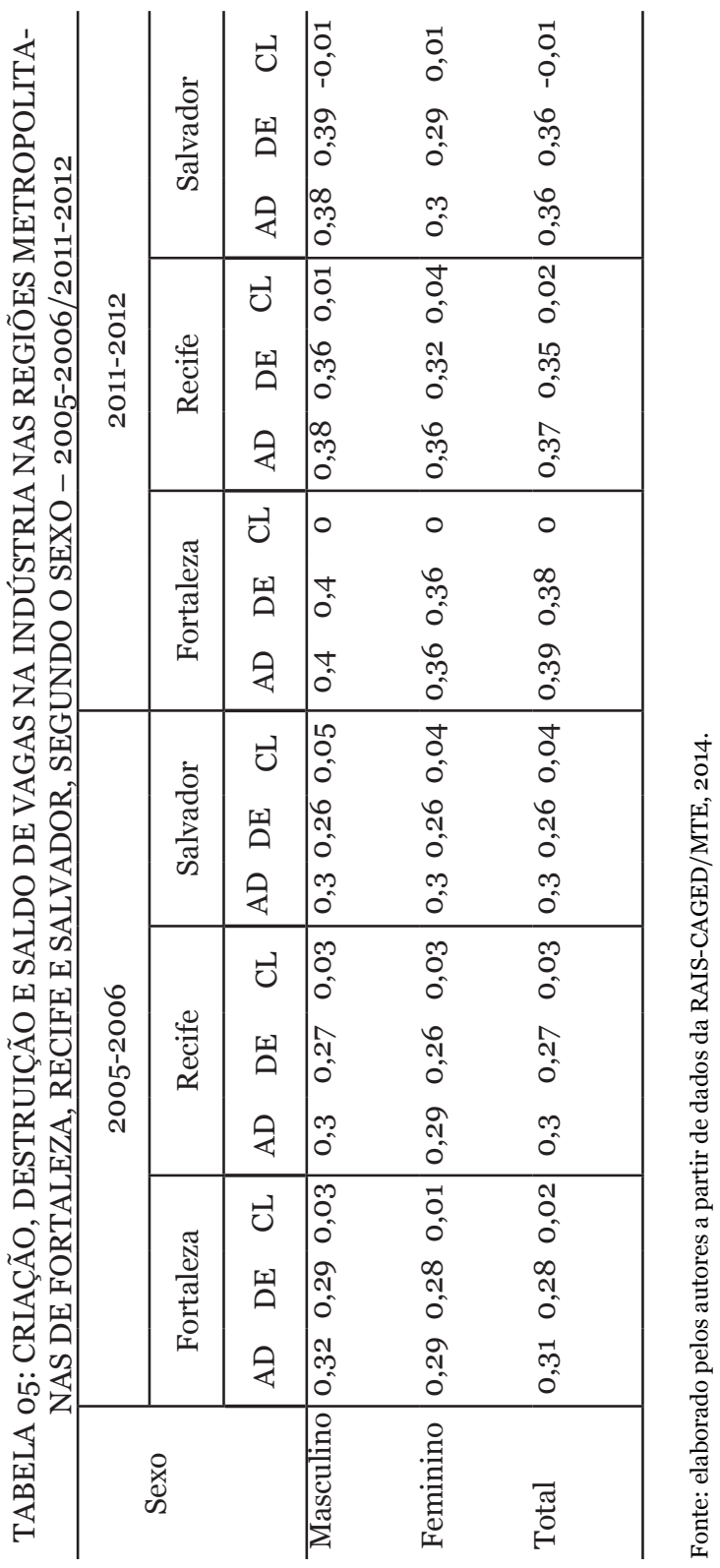


Já na grande Recife, pode-se constatar a ocorrência de queima de postos de trabalho apenas para aqueles com idade superior a 50 anos. Em Salvador, os registros conferem queima de postos de trabalho na indústria para aqueles com idade acima de 40 anos. O primeiro biênio (2005-2006) em análise confirma o que já foi ressaltado em outros estudos: a seletividade por idade no mercado de trabalho industrial metropolitano do Nordeste.

No segundo biênio (2011-2012), os registros indicam que a idade foi ainda mais determinante no movimento de entrada e saída da força de trabalho. Nas três regiões metropolitanas, os registros conferem queima de postos de trabalho em idade muito jovem dos ocupados formais na indústria, com destruição de postos de trabalho em faixa etária ainda menor do que as encontradas no primeiro biênio analisado. Na metropolitana de Fortaleza, os dados ratificam o observado no biênio anterior, e a queima de postos de trabalho ocorreu para aqueles com idade acima de 24 anos. Além do mais, é possível perceber que na grande Recife a queima foi registrada para os ocupados na indústria com idade a partir de 40 anos. Na metrópole de Salvador, registrou-se incidência semelhante ao observado na grande Fortaleza. A queima de postos de trabalho aconteceu para aqueles com idade acima de 24 anos.

Esses resultados corroboram os pressupostos da seletividade por idade no mercado de trabalho industrial metropolitano nordestino. Em outras palavras, as oportunidades de permanência em seus postos de trabalho acontecem para aqueles muito jovens e jovens, sendo que a força de trabalho com idade mais avançada fica mais vulnerável aos choques de mercado e funcionam como molas de ajustes.

Esses resultados corroboram os pressupostos da seletividade por idade no mercado de trabalho industrial metropolitano nordestino. Em outras palavras, as oportunidades de permanência em seus postos de trabalho acontecem para aqueles muito jovens e jovens, sendo que a força de trabalho com idade mais avançada fica mais vulnerável aos choques de mercado e funcionam como molas de ajustes. 
TABELA O6: CRIAÇÃO, DESTRUIÇÃO E SALDO DE VAGAS NA INDÚSTRIA NAS REGIÕES METROPOLITANAS DE FORTALEZA, RECIFE E SALVADOR, SEGUNDO A IDADE - 2005-2006/2011-2012

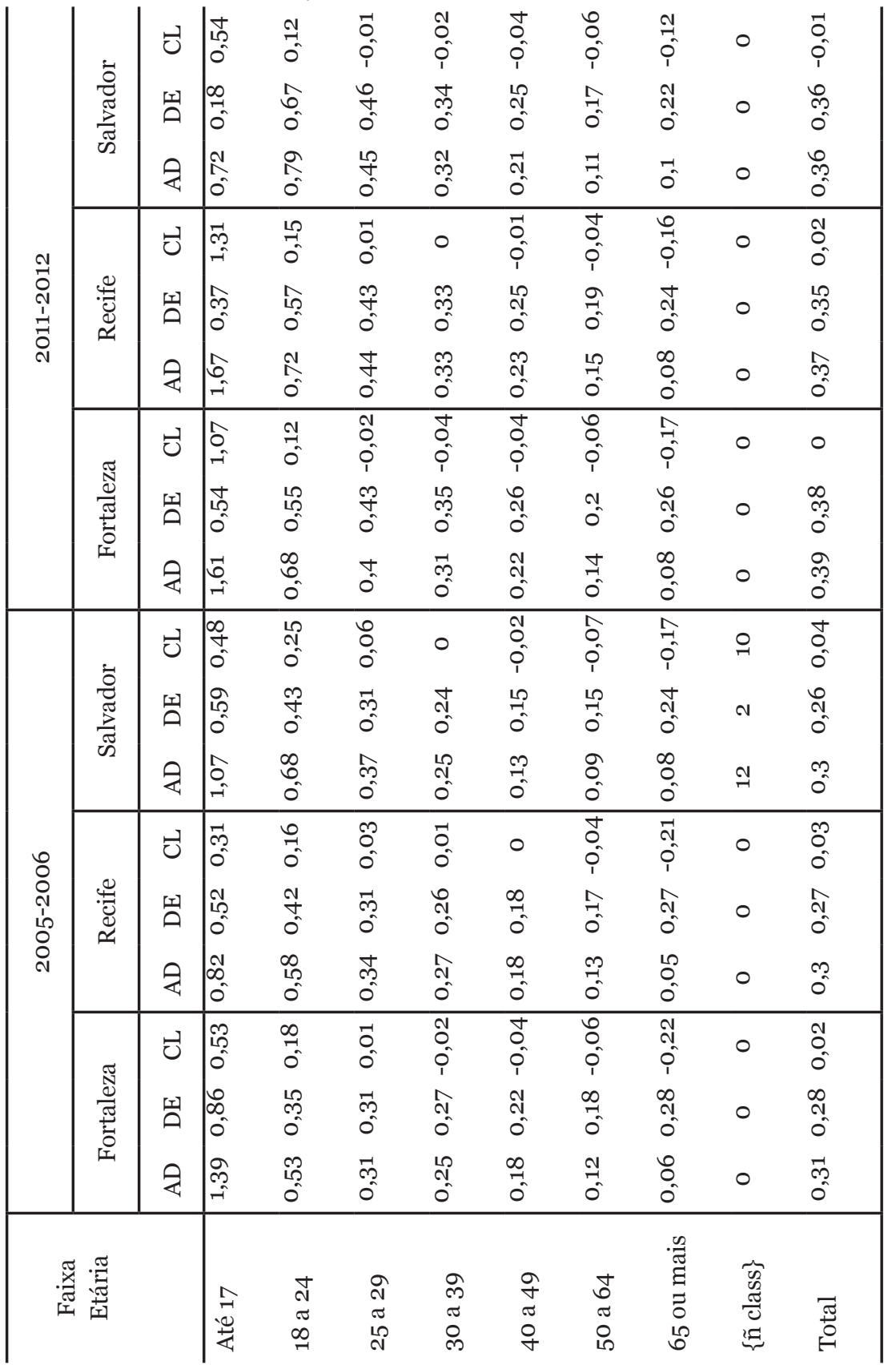

Fonte: elaborado pelos autores a partir de dados da RAIS-CAGED/MTE, 2014. 


\subsection{Caracterização socioeconômica}

A escolaridade da força de trabalho aparece como forte atributo para o alcance de um posto de trabalho, bem como a maior permanência no emprego na literatura econômica. Diante disso, os dados da tabela o7 têm a finalidade de demonstrar o comportamento da força de trabalho industrial metropolitana do Nordeste, a partir do grau de instrução formal 9 . Conforme pode ser observado, os registros confirmam que há, de fato, queima de postos de trabalho para os menos escolarizados na grande Fortaleza, no primeiro biênio em foco.

Houve queima de postos de trabalho para os analfabetos e para aqueles com escolaridade entre o $5^{\circ}$ ano completo do ensino fundamental ao ensino fundamental completo. Para os de menor nível de escolaridade, somente a faixa de até $05^{\mathrm{O}}$ ano completo do ensino fundamental apresentou criação líquida, embora muito pequena. Ainda, na metropolitana de Fortaleza, os dados indicam saldo apenas para aqueles com escolaridade superior ao ensino fundamental.

Na grande Recife, o primeiro biênio não se mostrou muito excludente para a força de trabalho menos escolarizada. Somente os analfabetos experimentaram queima de postos de trabalho na indústria entre 2005-2006. As demais faixas de escolaridade não tiveram saldo negativo. Todavia, a queima de postos de trabalho para os analfabetos foi relativamente acentuada, com índice na proporção de 0,14.

No mesmo período (2005-2006), a região metropolitana de Salvador acusou queima de postos de trabalho somente para aqueles com escolaridade entre $o$ $5^{\mathrm{O}}$ ano completo ao $9^{\circ}$ ano do ensino fundamental. As demais faixas lograram saldo positivo, embora que levemente, para a força de trabalho industrial com baixa escolaridade.

Outro fator relevante no mercado de trabalho industrial metropolitano nordestino é a predominância de baixos salários, em comparação a outras regiões do país. Além disso, a remuneração média da força de trabalho também é determinante nos ajustes macroeconômicos do mercado. Conforme pode ser observado nos registros plotados na tabela 08, a remuneração média da força de trabalho industrial nordestina tem forte influência na explicação da criação e destruição de postos de trabalho.

9 Considera-se aqui a instrução formal como sendo apenas a escolaridade (analfabeto ao ensino superior), sem levar em consideração a experiência adquirida no emprego, bem como a formação técnica do indivíduo. 
TABELA 07: CRIAÇÃO, DESTRUIÇÃO E SALDO DE VAGAS NA INDÚSTRIA NAS REGIÕES METROPOLITANAS DE FORTALEZA, RECIFE E SALVADOR, SEGUNDO A ESCOLARIDADE - 2005-2006/2011-2012.

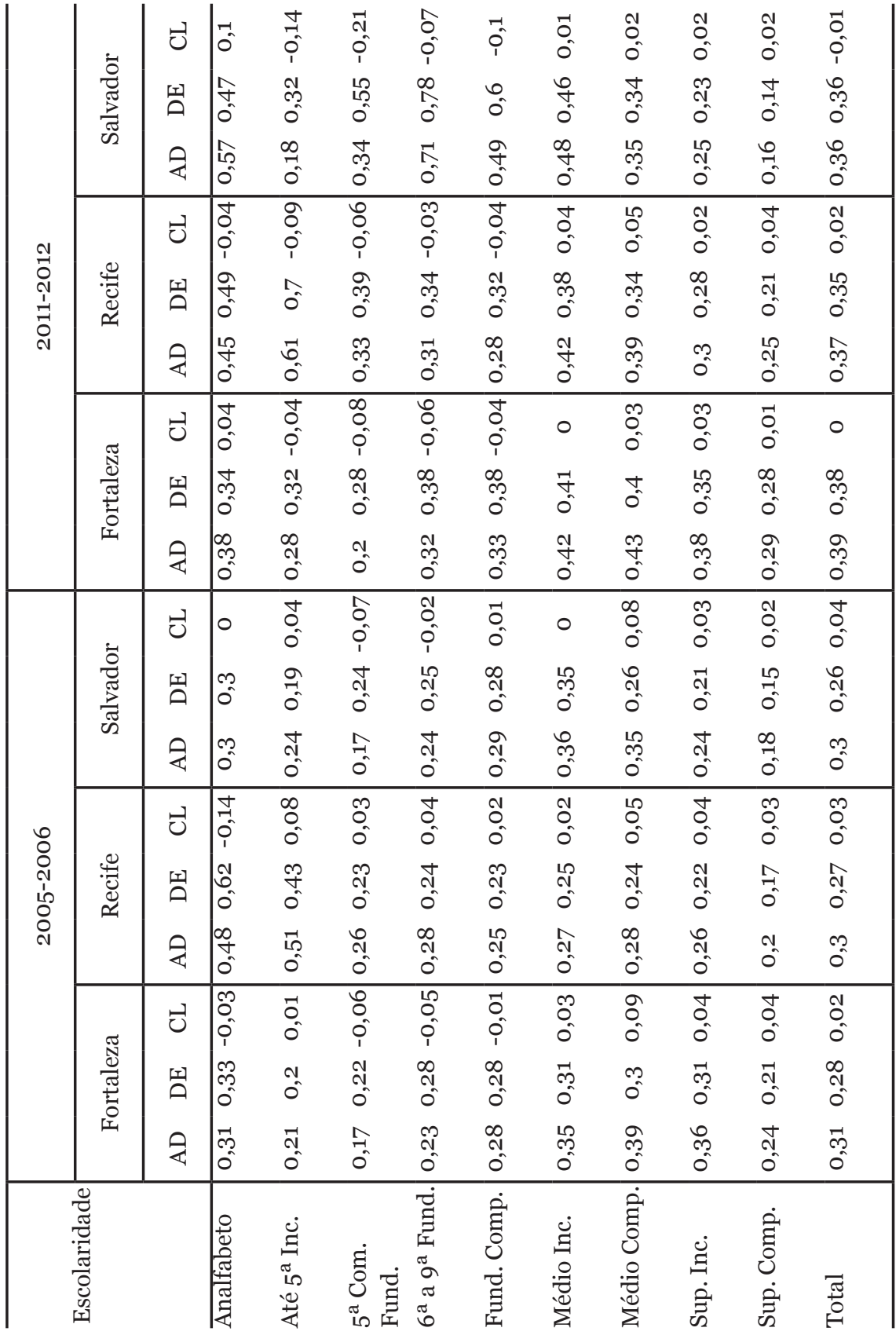

Fonte: elaborado pelos autores a partir de dados da RAIS-CAGED/MTE, 2014. 
Observe-se que, no primeiro biênio, na grande Fortaleza, o saldo líquido de vagas ocorreu, tão somente, para aqueles postos de trabalho que ofertavam remuneração média de até 1,0 salário mínimo. Nessa faixa de remuneração, a criação líquida de vagas foi de ordem de 0,68 (acentuadamente elevada). As demais faixas de remuneração, em maior ou menor intensidade, apresentaram queima de postos de trabalho.

Na metropolitana do Recife, constatou-se a mesma tendência do mercado de trabalho industrial da região metropolitana de Fortaleza. Porém, conforme conferem os indicadores, registrou-se saldo de vagas para os postos de trabalho que remuneravam até 2,o salários mínimos. As demais faixas também apresentaram queima de postos de trabalho no primeiro biênio em observação.

Semelhantemente, a grande Salvador repetiu os resultados encontrados na RMR. Criação líquida de vagas registrada apenas para aqueles postos de trabalho que ofertavam remuneração média de até 2,0 salários. As demais faixas de remuneração queimaram postos de trabalho no biênio 2005-2006.

No biênio 2011-2012, os resultados se repetem nas três regiões metropolitanas, variando apenas a intensidade com que o fenômeno foi registrado. As regiões metropolitanas de Fortaleza, Recife e Salvador reduziram o saldo de vagas nos postos de trabalho que remuneravam em até 1,0 salário mínimo. Além do mais, as duas últimas reduziram acentuadamente a criação líquida de vagas nos postos de trabalho que ofertavam remuneração entre 1,0 e 2,0 salários. Evidencia-se, assim, a maior intensidade da queima de postos de trabalho nas melhores faixas de remuneração.

Em função do exposto, percebe-se que o emprego industrial metropolitano no Nordeste torna-se acentuadamente seletivo em relação à idade, escolaridade e remuneração da força de trabalho. As características demográficas e os atributos socioeconômicos da população ocupada nas atividades industriais das três regiões metropolitanas em observação são fatores determinantes do movimento de entrada e de saída da população nas atividades produtivas industriais. 
TABELA 08: CRIAÇÃO, DESTRUIÇÃO E SALDO DE VAGAS NA INDÚSTRIA NAS REGIÕES METROPOLITANAS DE FORTALEZA, RECIFE E SALVADOR, SEGUNDO A FAIXA DE REMUNERAÇÃO - 2005-2006/2011-2012

\begin{tabular}{|c|c|c|c|c|c|c|c|c|c|c|c|}
\hline \multirow{3}{*}{$\begin{array}{l}\text { Ñ } \\
\text { N } \\
\text { ì } \\
\text { ते }\end{array}$} & 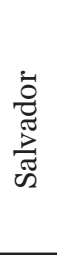 & $\begin{array}{l}\text { 己 } \\
\text { 됨 } \\
\theta\end{array}$ & 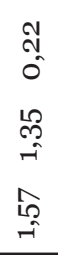 & $\begin{array}{l}0 \\
0 \\
0 \\
1 \\
12 \\
0 \\
10 \\
102 \\
0 \\
0\end{array}$ & 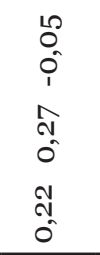 & $\begin{array}{l}2 \\
0 \\
0 \\
1 \\
+ \\
0 \\
0 \\
0 \\
0 \\
0\end{array}$ & $\begin{array}{l}0 \\
0 \\
1 \\
0 \\
0 \\
\hat{0} \\
0\end{array}$ & $\begin{array}{l}0 \\
0 \\
0 \\
1 \\
\hat{0} \\
0 \\
0 \\
0 \\
0 \\
0\end{array}$ & $\begin{array}{l}0 \\
0 \\
0 \\
0 \\
0 \\
0\end{array}$ & $\begin{array}{l}-1 \\
0 \\
1 \\
0 \\
0 \\
0 \\
0 \\
0 \\
0\end{array}$ & $\begin{array}{l}0 \\
0 \\
0 \\
0 \\
0 \\
0 \\
0 \\
0 \\
0 \\
0 \\
0\end{array}$ \\
\hline & $\begin{array}{l}\stackrel{\mathscr{C}}{\mathscr{D}} \\
\simeq\end{array}$ & $\begin{array}{l}\vec{U} \\
\text { 劉 } \\
\text { 完 }\end{array}$ & $\begin{array}{l}\tilde{N} \\
0 \\
0 \\
\hat{0} \\
0 \\
\hat{O} \\
0 \\
0\end{array}$ & $\begin{array}{l}0 \\
0 \\
0 \\
10 \\
1 \\
0 \\
0 \\
0 \\
0 \\
0\end{array}$ & $\begin{array}{l}\text { No } \\
0 \\
1 \\
\text { İ } \\
0 \\
0 \\
0 \\
0 \\
0\end{array}$ & $\begin{array}{l}10 \\
0 \\
0 \\
10 \\
0 \\
0\end{array}$ & 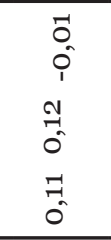 & $\begin{array}{l}\overrightarrow{0} \\
0 \\
1 \\
-1 \\
0 \\
ت \\
0\end{array}$ & $\begin{array}{c}\text { N } \\
0 \\
0 \\
1 \\
0 \\
0 \\
0 \\
0 \\
0 \\
0\end{array}$ & $\begin{array}{l}0 \\
0 \\
0 \\
1 \\
0 \\
0 \\
0 \\
= \\
0 \\
0\end{array}$ & $\begin{array}{l}0 \\
0 \\
0 \\
0 \\
10 \\
0 \\
0 \\
\hat{0} \\
0 \\
0\end{array}$ \\
\hline & 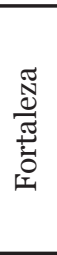 & $\begin{array}{l}\vec{U} \\
\text { 됨 } \\
\text { 룬 }\end{array}$ & 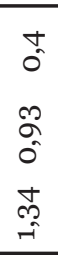 & $\begin{array}{l}0 \\
0 \\
0 \\
1 \\
\hat{n} \\
0 \\
0 \\
m \\
0 \\
0 \\
0\end{array}$ & $\begin{array}{l}0 \\
0 \\
1 \\
01 \\
01 \\
0 \\
\hat{0} \\
0\end{array}$ & $\begin{array}{l}0 \\
0 \\
1 \\
\hat{1} \\
0 \\
0 \\
0 \\
0\end{array}$ & $\begin{array}{l}7 \\
0 \\
0 \\
1 \\
10 \\
0 \\
0 \\
7 \\
0 \\
0\end{array}$ & \begin{tabular}{l}
0 \\
0 \\
0 \\
1 \\
\multirow{2}{*}{} \\
0 \\
0 \\
0 \\
0 \\
0
\end{tabular} & $\begin{array}{l}0 \\
0 \\
0 \\
1 \\
\tilde{0} \\
0 \\
0 \\
0 \\
0 \\
0\end{array}$ & $\begin{array}{l}\infty \\
0 \\
0 \\
10 \\
0 \\
0 \\
0 \\
0 \\
0\end{array}$ & $\begin{array}{l}\infty \\
\cdots \\
0 \\
0 \\
0 \\
0\end{array}$ \\
\hline \multirow{3}{*}{$\begin{array}{l}0 \\
0 \\
0 \\
\text { N } \\
1 \\
0 \\
0 \\
0\end{array}$} & \multirow[t]{2}{*}{ 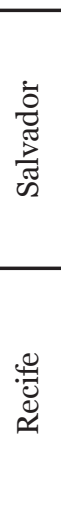 } & $\begin{array}{l}\overrightarrow{0} \\
\text { 됨 } \\
\text { 完 }\end{array}$ & 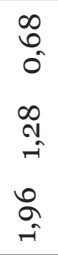 & \begin{tabular}{l}
$\infty$ \\
0 \\
0 \\
0 \\
\multirow{2}{*}{} \\
0 \\
0 \\
$y$ \\
$y$ \\
0
\end{tabular} & 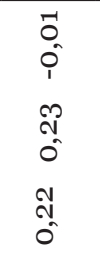 & $\begin{array}{l}\tilde{0} \\
0 \\
i \\
\cong \\
0 \\
0 \\
0 \\
0\end{array}$ & $\begin{array}{l}0 \\
0 \\
1 \\
0 \\
0 \\
0 \\
0 \\
0\end{array}$ & $\begin{array}{l}0 \\
0 \\
0 \\
1 \\
\hat{1} \\
0 \\
0 \\
0 \\
0 \\
0 \\
0\end{array}$ & $\begin{array}{l}0 \\
0 \\
i \\
0 \\
0 \\
0 \\
0 \\
0 \\
0 \\
0\end{array}$ & $\begin{array}{l}0 \\
0 \\
0 \\
1 \\
0 \\
0 \\
0 \\
0 \\
0 \\
0 \\
0\end{array}$ & $\begin{array}{l}0 \\
0 \\
0 \\
0 \\
0 \\
0 \\
0 \\
2 \\
0 \\
0\end{array}$ \\
\hline & & $\begin{array}{l}\text { ப } \\
\text { 됨 } \\
\text { 完 }\end{array}$ & $\begin{array}{l} \\
0 \\
0 \\
10 \\
0 \\
0 \\
1 \\
0 \\
0\end{array}$ & $\begin{array}{l}00 \\
0 \\
0 \\
0 \\
0 \\
7 \\
7 \\
0\end{array}$ & \begin{tabular}{l}
0 \\
0 \\
0 \\
1 \\
\multirow{2}{*}{} \\
0 \\
0 \\
0 \\
0
\end{tabular} & $\begin{array}{l}\text { ov } \\
0 \\
i \\
7 \\
0 \\
0 \\
0 \\
0 \\
0\end{array}$ & $\begin{array}{l}0 \\
0 \\
0 \\
\infty \\
0 \\
0\end{array}$ & $\begin{array}{l}0 \\
0 \\
0 \\
1 \\
0 \\
0 \\
0 \\
0 \\
0\end{array}$ & $\begin{array}{l}0 \\
0 \\
0 \\
0 \\
0 \\
0 \\
0 \\
0 \\
0\end{array}$ & $\begin{array}{l}\hat{0} \\
0 \\
\hat{0} \\
\hat{0} \\
0\end{array}$ & $\begin{array}{l}\infty \\
0 \\
0 \\
\hat{1} \\
0 \\
0 \\
\text { n. } \\
0\end{array}$ \\
\hline & $\begin{array}{l}\frac{\pi}{\mathbb{N}} \\
\frac{\pi}{\pi} \\
0 \\
0\end{array}$ & $\begin{array}{l}\text { Ð } \\
\text { 됩 } \\
\text { 원 }\end{array}$ & $\begin{array}{l}\infty \\
0 \\
0 \\
\sigma \\
\sigma \\
0 \\
0 \\
0 \\
10 \\
\end{array}$ & $\begin{array}{l}5 \\
0 \\
0 \\
1 \\
0 \\
\text { N1 } \\
0 \\
\text { J } \\
\text { N. } \\
0\end{array}$ & \begin{tabular}{l}
0 \\
0 \\
0 \\
1 \\
0 \\
0 \\
\multirow{0}{*}{} \\
0 \\
0
\end{tabular} & $\begin{array}{l}0 \\
0 \\
1 \\
0 \\
0 \\
0 \\
0 \\
0\end{array}$ & $\begin{array}{l}0 \\
0 \\
1 \\
0 \\
0 \\
0 \\
\infty \\
0 \\
0\end{array}$ & $\begin{array}{l}m \\
0 \\
i \\
0 \\
0 \\
0 \\
0\end{array}$ & $\begin{array}{l}10 \\
0 \\
1 \\
0 \\
0\end{array}$ & $\begin{array}{l}\infty \\
0 \\
0 \\
1 \\
0 \\
01 \\
0 \\
0 \\
0 \\
0\end{array}$ & 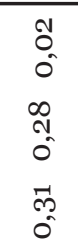 \\
\hline \multicolumn{3}{|c|}{ 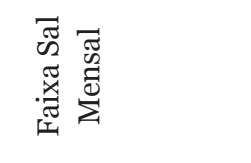 } & 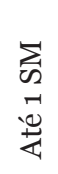 & 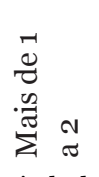 & 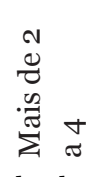 & 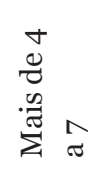 & 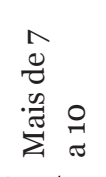 & 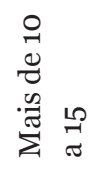 & $\begin{array}{l}10 \\
0 \\
0 \\
.0 \\
\tilde{\pi} \\
\Sigma\end{array}$ & 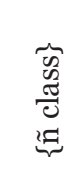 & $\begin{array}{l}\text { त् } \\
0 \\
\end{array}$ \\
\hline
\end{tabular}

Fonte: elaborado pelos autores a partir de dados da RAIS-CAGED/MTE, 2014. 


\section{Considerações finais}

O objetivo deste artigo foi analisar o comportamento do mercado de trabalho industrial metropolitano do Nordeste brasileiro nos biênios de 2005-2006 e 2011-2012. Levou-se em consideração o estoque de ocupados, bem como o fluxo da mão de obra formal. Além disso, foram observadas as taxas de criação, destruição e o saldo líquido de vagas, considerando-se as características demográficas e socioeconômicas da força de trabalho.

Verificou-se que a conjuntura do mercado de trabalho metropolitano se assemelha entre as RM em apreço. Todavia, a região metropolitana de Salvador se destaca entre as demais com o maior número de postos de trabalho formais, e a grande Fortaleza ocupa a última posição entre as três RM, ficando a grande Recife com a segunda colocação. Entretanto, no que se refere ao emprego industrial, a metropolitana de Fortaleza sobressai, visto que ela detém o maior estoque de ocupados formais no setor.

No que se refere ao tipo de admissão, a grande massa de ocupados enquadram-se na categoria de não admitido no ano calendário, ficando a ocupação por reemprego e por primeiro emprego na sequência por capacidade empregatícia. Adicionalmente, ressalta-se que as maiores taxas de criação líquida foram registradas na construção civil (metropolitana de Fortaleza), extrativa mineral e comércio (metropolitana de Recife) e extrativa mineral, indústria de transformação e comércio (metropolitana de Salvador), no primeiro biênio (2005-2006). No segundo intervalo, constataram-se mudanças importantes na dinâmica da criação líquida de vagas por setor de atividade, com destaque para a construção civil (metropolitana de Recife), comércio e serviços (metropolitana de Fortaleza), enquanto que a grande Salvador apresentou queima de postos de trabalho em muitos dos setores analisados.

Além do mais, tanto no primeiro quanto no último biênio em tela, o microestabelecimento industrial sobressaiu na geração de saldo de vagas nas três regiões metropolitanas. Em algumas das RM, o pequeno, o médio e o grande sofreram queima de postos de trabalho.

No tocante às características demográficas da força de trabalho industrial, a variável sexo não mostrou claramente discriminação entre homens e mulheres na geração de postos de trabalho industrial. Todavia, a idade é fator preponderante para determinar o movimento de entrada e saída no setor industrial metropolitano, sobretudo em Fortaleza e Salvador. Nessas RM, assistiu-se à queima de postos de trabalho para a população com idade acima de 24 anos, no último biênio em observação.

Já os atributos socioeconômicos da força de trabalho industrial das metrópoles nordestinas influenciaram acentuadamente a criação líquida de empregos. Os ocupados na indústria com menores níveis de escolaridade acabaram sendo atingidos pela queima de postos de trabalho em escala relativamente alta. Aco- 
plados a isso, os postos de trabalhos que remuneram as menores faixas foram os únicos que apresentaram saldo positivo de vagas nas três RM em apreço. Nas melhores faixas de remuneração, houve queima de postos de trabalho.

Diante disso, os dados mostram que há seletividade no mercado de trabalho industrial nordestino e que ainda se observam diferenças acentuadas das características demográficas e dos atributos socioeconômicos como determinantes das taxas de criação e, sobretudo, de destruição de postos de trabalho.

\section{Referencias bibliográficas}

Araújo, J. B. de. (2013). "Mercado de trabalho nas grandes regiões brasileiras nos anos 1990 e 2000". VII Congresso Latino-Americano de Estudos do Trabalho. Anais, São Paulo.

Araújo, T. B. (2000). “Nordeste, Nordestes. Que Nordeste?" Ensaios sobre o Desenvolvimento Brasileiro: heranças e urgências. Rio de Janeiro: Fase.

Arraes, A. K. de M.; Queiroz, S. N. De; Alves, C. L. B. (2008). "Mercado de trabalho formal na indústria: comparativo entre as regiões Nordeste e Sudeste nos anos de 1994 e 2004". Anais do II Encontro Internacional Trabalho e Formação de Trabalhadores. Fortaleza: Labor/UFC.

Baltar, P. E. De A.; Dedecca, C. S.; Henrique, W. (1996). Mercado de trabalho e exclusão social no Brasil. Crise e Trabalho no Brasil, modernidade ou volta ao passado? São Paulo: Scritta, 1996 - ( Pensiere).

Baltar, P. E., Proni, M. W. (1995). "Flexibilidade do trabalho, emprego e estrutura salarial no Brasil". Campinas, SP: Unicamp, cadernos do Cesit e texto para Discussão, 15 .

Bruschini, C (2007).. Trabalho e gênero no Brasil nos últimos dez anos. Cadernos de Pesquisa, v.37, $\mathrm{n}^{0}$ 132, p. 537-572. Set/dez, 2007.

Bruschini, C.; Puppin, A. B (2004). Trabalho de mulheres executivas no Brasil no final do século XX. Cadernos de Pesquisa, v.34, n.121, p.105-138, jan./abr. 2004.

Cacciamali, M. C (1992) Mudanças estruturais e na regulação do mercado de trabalho no Brasil nos anos 80. IPE/USP, maio 1992 (Texto para Discussão Interna, 6).

Cano, W (2002). Ensaios sobre a formação econômica regional do Brasil. Campinas - SP: Editora da UNICAMP, 2002.

Cano, W. (2008). "Desconcentração produtiva regional do Brasil - 1970-2005”. São Paulo: Editora UNESP.

Corbacho, A (2002). "Labor Markets in Central America: informal versus formal sectors". Harvard Institute for International Development, Development Discussion Papers, n. 747, 2000.

Carvalho, P. G. M.; Feijó, C. A. Do V. C. (1993). "Rotatividade do pessoal ocupado na indústria: sua evolução nos anos recentes - 1985-1993”. Anais da Associação Brasileira de Estudos do Trabalho.

Cassiolatto, J. E.; Britto, J. (2001). "Políticas industriais descentralizadas no caso brasileiro: uma breve análise da experiência recente”. In: ANAIS do Seminario 
sobre "Camino a la competitividad: El nivel meso y microeconómico" Santiago de Chile.

Cintra, M. A. M. (2005). "Suave Fracasso - a política macroeconômica brasileira entre 1999 e 2005”. Revista Novos Estudos.

Corseuil, C. H.; Ribeiro, E. P.; Santos, D. D.; Dias, R. (2002a). “Criação, destruição e realocação do emprego no Brasil”. Texto para discussão $N^{\circ} 855$, Rio de Janeiro, IPEA.

Corseuil, C. H.; Ribeiro, E. P.; Santos, D. D.; Dias, R. (2002b). “Job and worker flows in Brazil”. In: Menezes-Filho, N. A. (coord.). Labor market dynamics in Brazil. Final Report, 2nd draft, Part I, Inter-American Development Bank Research Network, 11th round, Fipe-USP.

Dedecca, C. S. (2005). Racionalização Econômica e Trabalho no Capitalismo Avançado. $2^{\mathrm{a}}$ Ed, Campinas, SP: Unicamp, IE.

Dedecca, C. S. (1998). “Reestruturação produtiva e tendenicas do emprego”. In :Marco Antonio de Oliveira (org). Economia e Trabalho, pp. 163-185, Campinas - SP: IE/Unicamp.

Dedecca, C. S.; Rosandiski, E. N. (2006). "Recuperação econômica e geração de empregos formais”. Revista Parcerias Estratégicas, n. 22.

Funkhouser, E. (1996). “The urban informal-sector in Central America: Household survey evidence”. World Development, v. 24 (11), pp. 1.737-1.751.

Furtado, Celso. Formação Econômica do Brasil (2007). $34^{\text {a }}$ Ed. São Paulo: Companhia das Letras, 2007.

Freije, S. "El empleo informal en America Latina y el Caribe: causas, consecuencias y recomendaciones de política” (2001). Banco Interamericano de Desarrollo, Primer Seminario Tecnico de Consulta Regional sobre Temas Laborales, 2001.

Galeano, E. V.; Merelles, A. E. F.; Wanderley, L. A. (2011). "Produtividade industrial do trabalho no estado da Bahia e nas regiões do Brasil entre 1996-2007”. Revista Desenbahia, v. 8 (15).

Guimarães Neto, L. (1997). "Desigualdade e políticas regionais no Brasil: caminhos e descaminhos”. Planejamento e políticas públicas, Brasília, IPEA, n. 15.

Hirata, H. (2009). “A precarização e a divisão internacional e sexual do trabalho". Revista Sociologias, ano 11, n⿳0 21, pp. 24-41.

Marcoullier, D.; Ruiz De Castilla, V.; Woodruff, C. (1997). "Formal measures of the informal-sector wage gap in Mexico, El Salvador and Peru". Economic development and cultural change, v. 45 (2), pp. 367-392.

Menezes, A. S. B. De; Carvalho, E. B. S. (1999). "Dimensões do desenvolvimento: teoria e prática no Nordeste brasileiro". Revista Econômica do Nordeste, v. 30 (2), pp. 234-245.

Miro, V. H.; Suliano. D. C. (2010). “Ceará: terra da luz para igualdade racial?” VI Encontro de Economia do Ceará em Debate, Anais..., Fortaleza.

Márquez, G.; Pagés, C. (1998). "Ties that Bind: Employment Erotection and Labor Market Outcomes in Latin America." Working Paper 373. Washington, DC, United States: Inter-American Development Bank. 
Orellano, V. I. F.; Pazello, E. T. (2006). "Evolução e determinantes da rotatividade da mão de obra nas firmas da indústria paulista na década de 1990". Revista Pesquisa e Planejamento Econômico, v.36 (1).

Ozorio De Almeida, A. L.; Alves, L. F.; Graham, S. M. (1995). "Poverty deregulation and employment in the informal sector of Mexico". World bank, education and social police department.

Pacheco, C. A. (1998). A fragmentação da nação, Campinas - SP, UNICAMP.

Pacheco, C. A. (1999). "Novos padrões de localização industrial? Tendências recentes dos indicadores de produção e do investimento industrial”, texto para discussão $N^{0} 633$ Brasília.

Pazello, E., Bivar, W., Gonzaga, G. (2000). “Criação e destruição de postos de trabalho por tamanho de empresa na indústria brasileira”. Pesquisa e Planejamento Econômico, , v. 30 (2), Rio de Janeiro.

Pochmann, M.. O trabalho sob fogo cruzado: exclusão, desemprego e precarização no final do século - São Paulo: contexto, 1999.

Pochmann, Márcio. Desemprego e politicas de emprego: tendências internacionais e o Brasil. In Marco Antonio de Oliveira (org). Economia e Trabalho, cap. 13, p. 219-233 - Campinas - SP: IE/Unicamp, 1998.

Pontes, P. A.; V., Pedro J. R.; Holanda, M. C. (2006). A Política de Atração de Investimentos Industriais do Estado do Ceará: uma análise do período de 1995 a 2005. Fortaleza, Dezembro.

Ribeiro, E. (2001). "Rotatividade de trabalhadores e criação e destruição de postos de trabalho: aspectos conceituais”. Texto para Discussão, 820, Rio de Janeiro: IPEA.

Silva Filho, L. A.; Amon-Há, R. (2011). "Perfil do desemprego recente na Região Metropolitana de Salvador - 2001-2008”. Revista Desenbahia, v. 8 (15).

Silva Filho, L. A.; Clementino, M do L. M. (2011). "Considerações sobre o perfil sócio-ocupacional nas regiões metropolitanas do Nordeste - 2001/2008”. XII Encontro Nacional de Estudos do Trabalho (ABET). Anais... João Pessoa - PB.

Silva Filho, L. A.. Mercado de Trabalho e Estrutura Sócio-ocupacional: estudo comparativo entre as regiões metropolitanas de Fortaleza, Recife e Salvador 2001-2008. Dissertação de Mestrado em Economia. Universidade Federal do Rio Grande do Norte, 2011, 131 p.

Silva Filho, L. A.; Mariano, J. L.; Queiroz, S. N (2012).. Emprego formal e rotatividade no mercado de trabalho agropecuário no Nordeste. $50^{\circ}$ congresso da Sociedade Brasileira de Economia, Administração e Sociologia Rural - SOBER, Anais..., vitória - ES, 2012.

Silva Filho, L. A.; Queiroz, S. N (2013).. Trabalhadores do roçado: a face oculta da produção canavieira no Brasil. VII Congresso Latino-Americano de Estudos do Trabalho - ALAS. Anais... São Paulo, 2013.

Silva, F. J. F. (2012). "Evolução do mercado de trabalho no Recife no período de 2003 a 2011". Revista da Abet, v. 6(2). 